\title{
Special Issue "Genetic Advances in Neuromuscular Disorders: From Gene Identification to Gene Therapy"
}

\author{
Virginia Arechavala-Gomeza ${ }^{1,2, *(\mathbb{D})}$ and Lidia Gonzalez-Quereda ${ }^{3}$ (D) \\ 1 Neuromuscular Disorders Group, Biocruces Bizkaia Health Research Institute, 48903 Barakaldo, Spain \\ Ikerbasque, Basque Foundation for Science, 48009 Bilbao, Spain \\ 3 CIBERER, Universitat Autónoma de Barcelona (UAB) IIB Sant Pau, Hospital de Sant Pau, \\ 08041 Barcelona, Spain; lgonzalezq@santpau.cat \\ * Correspondence: virginia.arechavalagomeza@osakidetza.eus
}

\section{check for}

updates

Citation: Arechavala-Gomeza, V.; Gonzalez-Quereda, L. Special Issue “Genetic Advances in Neuromuscular Disorders: From Gene Identification to Gene Therapy". Genes 2021, 12, 242. https://doi.org/10.3390/ genes12020242

Received: 5 February 2021

Accepted: 7 February 2021

Published: 8 February 202

Publisher's Note: MDPI stays neutral with regard to jurisdictional claims in published maps and institutional affiliations.

Copyright: (C) 2021 by the authors Licensee MDPI, Basel, Switzerland. This article is an open access article distributed under the terms and conditions of the Creative Commons Attribution (CC BY) license (https:// creativecommons.org/licenses/by/ $4.0 /)$.
Since the gene responsible for Duchenne muscular dystrophy was first described in 1987 [1], knowledge of neuromuscular diseases (NMD) has evolved rapidly. Advances in molecular genetics and an ongoing revolution in diagnostic techniques have facilitated the identification of a large number of causative genes in recent years and treatments are being developed against many new targets. However, the large number of genes related to these diseases, some of them of great size and complexity, as well as the high clinical and genetic heterogeneity that these entities usually present, pose a challenge for clinicians and researchers when defining all the intricacies that make up these diseases.

This Special Issue "Genetic Advances in Neuromuscular Disorders: From Gene Identification to Gene Therapy" includes 15 high-quality papers that seek to deepen the knowledge of multiple aspects related to some of the most prevalent and disabling neuromuscular diseases.

At a time when the development of gene therapy is booming and various mutationdependent therapies are becoming available [2], establishing a detailed natural history of these entities, determining a specific genetic cause, and understanding molecular defects are of utmost importance. In this regard, the work of Knyazeva et al. extends the knowledge of the role of Filamin C (FLNC) in muscle cells, focusing on muscle alterations developed after FLNC loss. The authors confirm the role of FLNC in the regulation of essential muscle processes such as muscle cell proliferation, migration, and differentiation [3]. Jorholt et al. contribute to the clinical knowledge of ALPK3-associated cases by reporting two new cases of hypertrophic cardiomyopathy with muscle involvement and variability in age of onset [4]. Knowing the factors involved in the pathogenesis and progression of these diseases is paramount for their prevention, management, and treatment. Interestingly, the work of Ignatieva et al. demonstrates how LMNA mutations associated with different clinical phenotypes affect the molecular mechanisms involved in skeletal muscle differentiation and metabolism [5]. With the aim of achieving a rapid and cost-effective genetic diagnosis, the work of Alcántara-Ortigoza et al. proposes an combination of multiplex ligation-dependent probe amplification (MLPA) and Next-Generation Sequencing (NSG) as a first-line diagnostic approach for Mexican patients with muscular dystrophy, displacing muscle biopsy to a second tier of the diagnostic process [6]. Taking advantage of new technologies also, Gonzalez-Quereda et al. analyze the mutational spectrum of a cohort of 207 patients suffering from NMD by evaluating a custom targeted resequencing neuromuscular gene panel as a diagnostic tool. They established a conclusive genetic diagnosis in about $50 \%$ of patients, with RYR 1 and TTN accounting for almost $30 \%$ of cases [7]. Mroczek et al. review the particular molecular structure of PLEC, as well as its tissue-specific functions and associated phenotypes. The authors also investigate the role of plectin deficiency in congenital myasthenic syndromes by describing four patients carrying the PLEC c.1_9 mutation in homozygosity and suggesting a common origin of the 
mutation [8]. García-Solaesa et al. describe, for the first time in a Spanish population, a new splice variant associated with a myopathic form of PGK1 deficiency. The authors also provide an interesting discussion on the dichotomization of PGK1 into myopathic forms without anemia and hemolytic forms [9].

One of the challenges of medicine is to identify physiological or pathological processes through the use of biomarkers that are specific, sensitive, and predictive. The work of Pegoraro and Angelini determines the role of miR206 in muscle recovery and regeneration, pointing to it as an easily accessible circulating biomarker for prognosis to monitor the progression of muscle damage in limb-girdle muscular dystrophies [10]. With regard to one of the most frequent and disabling muscular dystrophies of childhood, Duchenne muscular dystrophy, several studies allow us to deepen our knowledge of various aspects of the disease. Lim. et al. review the literature on cardiac involvement in DMD symptomatic women and discuss the implications of studies of female DMD carriers in the development of therapies aimed at increasing cardiac dystrophin levels [11]. The work of Chengmei et al. reviews the current status of DMD pathogenesis and therapy, focusing on the mutational spectrum; diagnostic tools, clinical trials, and therapeutic approaches; and also evaluating the clinical potential of new advanced therapeutic strategies [12]. Lim. et al. review the animal models developed for DMD that have been created using CRISPR-based technology, a topic of special interest, given that having reliable animal models is key to exploring new therapeutic targets [13].

DM1 is one of the most common adult forms of muscular dystrophy and the expansion of a specific trinucleotide sequence (CTG) is the molecular pathological mechanism responsible for its clinical manifestations. Expansions can be large and complex and, even today, their correct characterization in size and composition is a diagnostic challenge. On this topic, Ballester-Lopez et al. compare five different approaches to estimate CTG expansion size in 15 patients with DM1. They found variability between the methods used and, based on their results, propose small pool (SP)-PCR as the most appropriate technique [14]. Castro et al. review advances in the understanding of the pathogenic mechanisms associated with repeat expansion neurodegenerative and neuromuscular diseases, focusing on the impact of antisense repeat transcription in the development of new therapies [15]. López-Martinez et al. review the role of tissue-specific regulators of alternative splicing of MBNL and CELF1, and describe the molecular mechanisms underlying the misregulation of this process. In addition, they provide a list of transcriptional alterations implicated in the pathogenesis of DM1 [16]. The work of Ballester-Lopez et al. studies the variability of CTG expansion in three different tissues (blood, muscle, and skin) from eight patients with DM1 and its association with the patient's clinical characteristics. They suggest that progenitor CTG size, measured in muscle tissue, is associated with age at disease onset and functional impairment of muscle [17].

In summary, this Special Issue delves into some of the most relevant aspects concerning neuromuscular diseases today, offering an overview of the current landscape and shedding light on the path from gene identification to gene therapy.

Funding: V.A.-G. holds a Miguel Servet Fellowship from the ISCIII (CPII17/00004), part-funded by ERDF/FEDER. V.A.-G. also acknowledges funding from Ikerbasque (Basque Foundation for Science). L.G.-Q. received a grant from FIS PI18/01585, funded by ISCIII and FEDER: ‘Una manera de hacer Europa'.

Conflicts of Interest: The authors declare no conflict of interest. 


\section{References}

1. Koenig, M.; Hoffman, E.P.; Bertelson, C.J.; Monaco, A.P.; Feener, C.; Kunkel, L.M. Complete cloning of the Duchenne muscular dystrophy (DMD) cDNA and preliminary genomic organization of the DMD gene in normal and affected individuals. Cell 1987, 50, 509-517. [CrossRef]

2. Abreu, N.J.; Waldrop, M.A. Overview of gene therapy in spinal muscular atrophy and Duchenne muscular dystrophy. Pediatr. Pulmonol. 2020. [CrossRef] [PubMed]

3. Knyazeva, A.; Khudiakov, A.; Vaz, R.; Muravyev, A.; Sukhareva, K.; Sejersen, T.; Kostareva, A. FLNC Expression Level Influences the Activity of TEAD-YAP/TAZ Signaling. Genes 2020, 11, 1343. [CrossRef]

4. Jorholt, J.; Formicheva, Y.; Vershinina, T.; Kiselev, A.; Muravyev, A.; Demchenko, E.; Fedotov, P.; Zlotina, A.; Rygkov, A.; Vasichkina, E.; et al. Two New Cases of Hypertrophic Cardiomyopathy and Skeletal Muscle Features Associated with ALPK3 Homozygous and Compound Heterozygous Variants. Genes 2020, 11, 1201. [CrossRef]

5. Ignatieva, E.V.; Ivanova, O.A.; Komarova, M.Y.; Khromova, N.V.; Polev, D.E.; Kostareva, A.A.; Sergushichev, A.; Dmitrieva, R.I. LMNA Mutations G232E and R482L Cause Dysregulation of Skeletal Muscle Differentiation, Bioenergetics, and Metabolic Gene Expression Profile. Genes 2020, 11, 1057. [CrossRef]

6. Alcántara-Ortigoza, M.A.; Reyna-Fabián, M.E.; González-del Angel, A.; Estandia-Ortega, B.; Bermúdez-López, C.; CruzMiranda, G.M.; Ruíz-García, M. Predominance of Dystrophinopathy Genotypes in Mexican Male Patients Presenting as Muscular Dystrophy with A Normal Multiplex Polymerase Chain Reaction DMD Gene Result: A Study Including Targeted Next-Generation Sequencing. Genes 2019, 10, 856. [CrossRef]

7. Gonzalez-Quereda, L.; Rodriguez, M.J.; Diaz-Manera, J.; Alonso-Perez, J.; Gallardo, E.; Nascimento, A.; Ortez, C.; Naterade Benito, D.; Olive, M.; Gonzalez-Mera, L.; et al. Targeted Next-Generation Sequencing in a Large Cohort of Genetically Undiagnosed Patients with Neuromuscular Disorders in Spain. Genes 2020, 11, 539. [CrossRef] [PubMed]

8. Mroczek, M.; Durmus, H.; Topf, A.; Parman, Y.; Straub, V. Four Individuals with a Homozygous Mutation in Exon 1f of the PLEC Gene and Associated Myasthenic Features. Genes 2020, 11, 716. [CrossRef] [PubMed]

9. Garcia-Solaesa, V.; Serrano-Lorenzo, P.; Ramos-Arroyo, M.A.; Blazquez, A.; Pagola-Lorz, I.; Artigas-Lopez, M.; Arenas, J.; Martin, M.A.; Jerico-Pascual, I. A Novel Missense Variant Associated with A Splicing Defect in A Myopathic Form of PGK1 Deficiency in The Spanish Population. Genes 2019, 10, 785. [CrossRef] [PubMed]

10. Pegoraro, V.; Angelini, C. Circulating miR-206 as a Biomarker for Patients Affected by Severe Limb Girdle Muscle Dystrophies. Genes 2021, 12, 85. [CrossRef] [PubMed]

11. Lim, K.R.Q.; Sheri, N.; Nguyen, Q.; Yokota, T. Cardiac Involvement in Dystrophin-Deficient Females: Current Understanding and Implications for the Treatment of Dystrophinopathies. Genes 2020, 11, 765. [CrossRef] [PubMed]

12. Sun, C.; Shen, L.; Zhang, Z.; Xie, X. Therapeutic Strategies for Duchenne Muscular Dystrophy: An Update. Genes 2020, 11, 837. [CrossRef] [PubMed]

13. Lim, K.R.Q.; Nguyen, Q.; Dzierlega, K.; Huang, Y.; Yokota, T. CRISPR-Generated Animal Models of Duchenne Muscular Dystrophy. Genes 2020, 11, 342. [CrossRef] [PubMed]

14. Ballester-Lopez, A.; Linares-Pardo, I.; Koehorst, E.; Nunez-Manchon, J.; Pintos-Morell, G.; Coll-Canti, J.; Almendrote, M.; Lucente, G.; Arbex, A.; Magana, J.J.; et al. The Need for Establishing a Universal CTG Sizing Method in Myotonic Dystrophy Type 1. Genes 2020, 11, 757. [CrossRef] [PubMed]

15. Castro, A.F.; Loureiro, J.R.; Bessa, J.; Silveira, I. Antisense Transcription across Nucleotide Repeat Expansions in Neurodegenerative and Neuromuscular Diseases: Progress and Mysteries. Genes 2020, 11, 1418. [CrossRef] [PubMed]

16. López-Martínez, A.; Soblechero-Martín, P.; de-la-Puente-Ovejero, L.; Nogales-Gadea, G.; Arechavala-Gomeza, V. An Overview of Alternative Splicing Defects Implicated in Myotonic Dystrophy Type I. Genes 2020, 11, 1109. [CrossRef] [PubMed]

17. Ballester-Lopez, A.; Koehorst, E.; Linares-Pardo, I.; Nunez-Manchon, J.; Almendrote, M.; Lucente, G.; Arbex, A.; Puente, C.; Lucia, A.; Monckton, D.G.; et al. Preliminary Findings on CTG Expansion Determination in Different Tissues from Patients with Myotonic Dystrophy Type 1. Genes 2020, 11, 1321. [CrossRef] [PubMed] 